\title{
Prototype Alat Olah Limbah Cair Laboratorium dengan Prinsip Fisika, Kimia dan Biologi dengan Hasil Akhir yang Aman Dibuang dan Tidak Mencemari Lingkungan
}

\author{
Saipul Bahri ${ }^{1 *}$, Sumayya Syarafina ${ }^{2}$, Seli Tamara ${ }^{3}$, Venesa Thalia Putri ${ }^{4}$, \\ Muhammad Naufal Chandra Halim ${ }^{5}$, Putri Novitasari ${ }^{6}$ \\ 1,2,3,4,5,6 Politeknik Negeri Cilacap, Teknik Pengendalian Pencemaran Lingkungan \\ *Email: saipultekim2010@gmail.com
}

\begin{abstract}
Background: Laboratory of Chemical Engineering Environmental Pollution is one of the laboratories that produce liquid waste. However, during this treatment, liquid waste is only stored in a temporary storage area. It will cause part and quality of wastewater produced. It is necessary to research the design of laboratory-scale sports equipment to minimize pollution due to the accumulation of wastewater in conditions without maintenance. Aims this study is to build prototype waste liquid processing equipment. Methods: in its design, this tool applied three methods of physical, chemical and biological. This tool will be applied in management using coagulation, electrocoagulation, adsorption, and phytoremediation technologies. Results: This tool can work optimally with an initial capacity of 45 Liters. The parameters tested were pH, TDS, Total Hardness and Lead. The test is carried out to find out the rate of decrease of parameters in each process and the decrease parameter. Conclusion: After testing, it was proven that the biggest decrease in the adsorption process and the result of the calculation of the biggest decrease in TDS was $72.64 \%$. The existence of this tool is expected to overcome the presence of accumulation of liquid waste in the laboratory so that no environmental pollution occurs.
\end{abstract}

Keywords: effectiveness, laboratory liquid waste, waste processing equipment

\section{PENDAHULUAN}

Laboratorium kimia merupakan laboratorium yang umum digunakan pada setiap kegiatan yang berhubungan dengan zat-zat kimia baik di lembaga pemerintah atau swasta, lembaga pendidikan, penelitian dan lain-lain. Operasional laboratorium ini secara kontinyu akan menghasilkan berbagai jenis limbah baik organik maupun anorganik (Audiana, Apriani, \& Kadaria, 2017). Dengan wujud cair atau padat.

Limbah laboratorium yang berwujud cairan sebagian besar merupakanlimbah bahan berbahaya dan beracun (B3). Berdasarkan peraturan pemerintah tentang Limbah ini, setiap penghasil limbah harus melakukan pengelolaan pada limbah tersebut (Harjanto \& Saipul, 2019). Limbah yang berwujud cair pada laboratorium umumnya mengandung logam berat yang disertai parameterparameter limbah lainnya yang masih berada di atas ambang batas misalnya nilai COD dan BOD (Nuraini dkk, 2019). Limbah cair ini memerlukan pengolahan sebelum dapat dibuang secara langsung ke badan air agar tidak merusak lingkungan. Limbah yang dihasilkan memiliki potensi yang bahaya dan/atau beracun yang dapat mencemari atau merusak lingkungan baik secara langsung maupun tidak langsung (Subamia, I.D.P, et al. 2016). Namun, pada kenyataannya sampai saat ini belum banyak laboratorium yang memiliki instalasi pengolahan air limbah (IPAL) karena disebabkan berbagai faktor, misalnya teknik pengolahan yang efektif dengan biaya yang tidak terlampau mahal.

Terkait dengan metode pengolahan limbah, telah banyak penelitian-penelitian sebelumnya yang berhubungan dengan 
metode-metode pengolahan limbah yang umum dikenal yakni metode fisika, kimia dan biologi. Metode fisika dilakukan dengan teknik filtrasi, sedimentasi atau teknik lainnya yang dilakukan secara fisis sedangkan metode kimia kebanyakan menggunakan teknik flokulasi atau koagulasi dengan menggunakan flokulan atau koagulan dan metode biologi dilakukan dengan menggunakan bakteri (Indrayani dan Rahmah, 2018). Metode yang lebih terbaru dalam hal pengolahan limbah yakni metode fisika-kimia yang menggunakan elektrokoagulasi dan metode biologi yang menggunakan media tumbuhan atau fitoremediasi.

Pada metode elektrokoagulasi, terjadi reaksi oksidasi dan reduksi pada kedua elektroda yang digunakan (pada kutub positif dan negative elektroda) (Yulianto, Hakim, Purwaningsih, \& Pravitasari, 2009). Nur dan Jatnika (2014) menggunakan metode elektrokoagulasi untuk melakukan pengolahan limbah domestik dengan menggunakan aluminium sebagai elektrodanya. Metode elektrokoagulasi terbukti juga lebih efektif jika dibandingkan dengan metode koagulasi konvensional dalam hal reduksi kandungan minyak pada limbah (Prabowo et al, 2012). Metode elektrokoagulasi dapat menurunkan nilai COD pada limbah tahu sampai 97,25\% (Ananda dkk, 2017). Pada pengolahan limbah sawit, metode elektrokoagulasi akan menghasilkan hasil olahan limbah yang sudah memenuhi baku mutu limbah cair (Hanum dkk, 2015).

Metode yang lain yakni fitoremediasi. Fitoremediasi adalah metode pemanfaatan tumbuhan atau tanaman untuk menghilangkan atau mereduksi limbah baik yang dilakukan secara in-situ atau yang dilakukan secara ex-situ (Rosyidah, 2014).

Metode ini juga telah banyak dikembangkan untuk penguraian limbah cair. Ratnawati dan Fatmasari (2018) menggunakan metode fitoremediasi untuk menghilangkan logam berat pada limbah.Tanaman Hanjuang dapat digunakan untuk metode fitoremediasi pengambilan logam berat pada limbah (Nurlela dan Wardoyo, 2019). Tanah yang sudah tercemar logam berat juga dapat dibersihkan dengan metode fitoremediasi (Siahaan et al, 2014).

Pada penelitian ini digunakan metode gabungan antara adsorbsi, sedimentasi, elektrokoagulasi dan fitoremediasi. Dengan penggabungan beberapa metode ini diharapkan akan menghasilkan prototype alat olah limbah yang lebih efektif.

\section{METODE PENELITIAN}

Kegiatan pada penelitian ini dibagi menjadi beberapa tahapan yakni tahap pertama berupa identifikasi awal, tahap kedua berupa perancangan alat dan tahap terakhir yaitu interpretasi hasil dan penyusunan simpulan. Pada tahap identifikasi awal dilakukan tahapan pengambilan limbah cair awal. Pada tahap pengambilan limbah cair awal, dilakukan identifikasi karakteristik. Identifikasi awal ini dilakukan untuk mengetahui kondisi limbah awal yang berguna bagi penyusunan tahapan atau proses-proses untuk mereduksi atau menurunkan kadar parameter pencemar yang ada dalam limbah tersebut. Untuk identifikasi awal limbah cair Laboratorium diambil dari Laboratorium Kimia Teknik Pengendalian Pencemaran Lingkungan Politeknik Negeri Cilacap. Tahap pengujian dilakukan di Laboratorium Dinas Lingkungan Hidup Kabupaten Cilacap. 
Perancangan prototype alat pengolahan limbah (Gambar 1.) yaitu bak pengolahan limbah cair ini penampungan awal, bak koagulasi, bak menggabungkan beberapa metode yang elektrokoagulasi, bak penampungan efektif untuk pengolahan limbah cair sementara/sedimentasi, pipa adsorpsi dan laboratorium. Adapun susunan alat bak fitoremediasi.

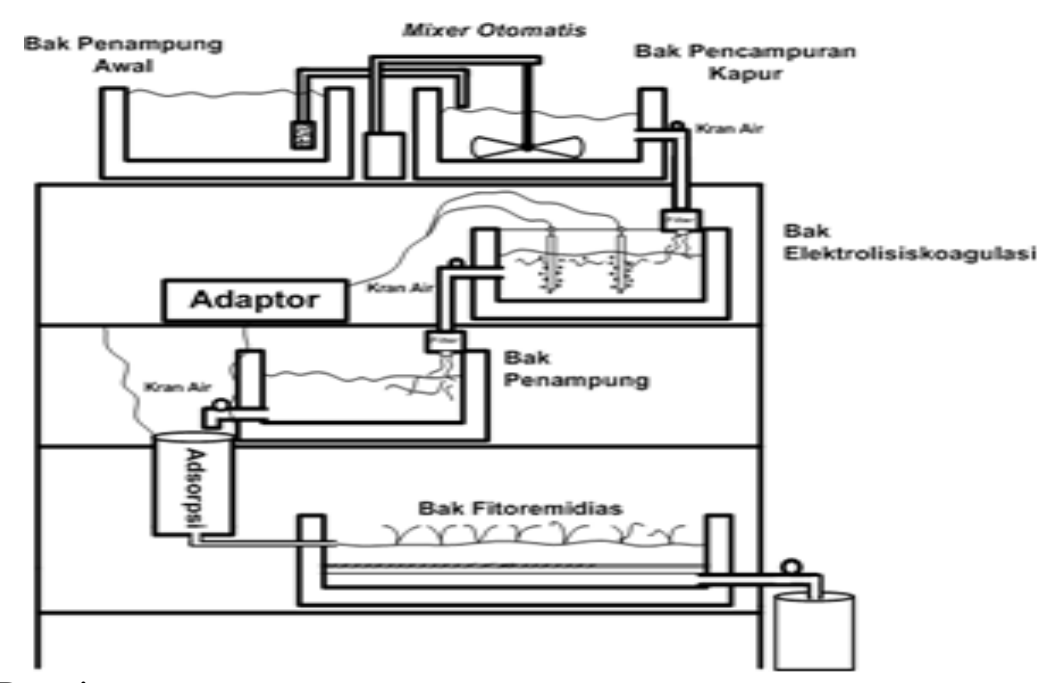

Gambar 1. Desain prototype

Kegiatan Penelitian ini dilakukan di Laboratorium kimia Politeknik Negeri Cilacap. Limbah dari Laboratorium Kimia Politeknik Negeri Cilacap yang sudah diidentifikasi dialirkan ke dalam bak penampungan awal, selanjutnya dialirkan menuju bak koagulasi. Pada bak koagulasi limbah diberi campuran koagulan berupa $\mathrm{CaCo} 3$ atau susu kapur. Setelah itu limbah akan memasuki bak elektokoagulasi untuk dialiri arus listrik yang dialirkan melalui lempengan lumunium yang tercelup kedalam limbah cair laboratorium.

Selanjutnya limbah cair akan dialirkan kedalam bak penampungan sementara, bak ini bertujuan untuk kembali mengendapkan flok-flok dari bak elektrokoagulasi yang lolos dari saringan. Aliran kemudian diteruskan kedalam pipa berisikan adsorben berupa zeolit dan karbon aktif untuk menjerap kandungan dari limbah cair, sekaligus menghilangkan bau dan menjernihkan warna limbah Dari pipa adsopsi limbah akan langsung mengalir kedalam bak fitoremediasi dengan waktu tinggal selama 2-3 hari agar tanaman fitoremidiasi dapat menyerap kandungan limbah cair laboratorium secara optimal.

Standar pengujian kualitas air yang merupakan hasil pengolahan pada kegiatan ini menggunakan Standar Nasional Indonesia (SNI) dan pengujian skala laboratorium. Adapun parameter pengujian yang dianlisis yakni parameter uji fisika dan parameter uji kimia.

Pada tahap interpretasi hasil dan simpulan dilakukan perhitungan efektifitas alat sehingga didapatkan hasil efektifitas penurunan parameter yang paling besar dan efektifitas penurunan parameter pada setiap proses. Metode uji dalam kegiatan pengujian kualitas air hasil treatment alat pengolahan limbah cair laboratorium mengacu pada Standar 
Nasional Indonesia (SNI), pengukuran skala laboraborium dan uji organoleptik.

\section{HASIL PENELITIAN}

Berdasarkan identifikasi awal limbah cair laboratorium diketahui hasil uji parameter sebagai berikut :

Tabel 1. Karakteristik Awal Sampel Limbah Cair Laboratorium Kimia

\begin{tabular}{lcccc}
\hline \multirow{2}{*}{ Parameter } & Satuan & Hasil Uji & \multicolumn{2}{c}{ Baku Mutu Air Limbah } \\
\cline { 3 - 5 } & & & Kermen LH No.5 Tahun 2014 \\
\hline Warna & - & Gecoklatan & - & Golongan II \\
Bau & - & 2 & - & - \\
pH & - & 53000 & $6,0-9,0$ & $6,0-9,0$ \\
TDS & mg/L & 304 & 2000 & 4000 \\
Kesadahan Total & mg/L & $<0.251$ & - & - \\
Timbal & mg/L & $<, 1$ & 1 \\
\hline
\end{tabular}

Karakteristik awal limbah masih antara lain metode fisika, kimia maupun jauh dari baku mutu yang telah ditetapkan metode biologi yang secara teknis berupa sehingga perlu diolah dengan teknik koagulasi, elektrokoagulasi, menggunakan teknik-teknik pengolahan adsorpsi dan fitoremediasi dan lain-lain. limbah yang efektif antara lain dengan Berikut merupakan data penurunan menggunakan metode-metode yang umum parameter $\mathrm{pH}$ dan TDS pada setiap proses digunakan untuk pengolahan limbah yang tertera pada Tabel 2.

Tabel 2. Penurunan $\mathrm{pH}$ dan TDS Prototype alat olah limbah cair Laboratorium

\begin{tabular}{|c|c|c|}
\hline \multirow{2}{*}{ Bak Container } & \multicolumn{2}{|c|}{ Parameter Uji } \\
\hline & $\mathbf{p H}$ & TDS (ppm) \\
\hline Penampungan Awal & 2 & $530 \times 10 \mathrm{ppm}$ \\
\hline Koagulasi & 12,2 & 495 x $10 \mathrm{ppm}$ \\
\hline Elektrokoagulasi & 11 & $425 \times 10 \mathrm{ppm}$ \\
\hline Adsorpsi & 8,5 & $245 \times 10 \mathrm{ppm}$ \\
\hline Fitoremidiasi & 7,3 & $145 \times 10 \mathrm{ppm}$ \\
\hline
\end{tabular}




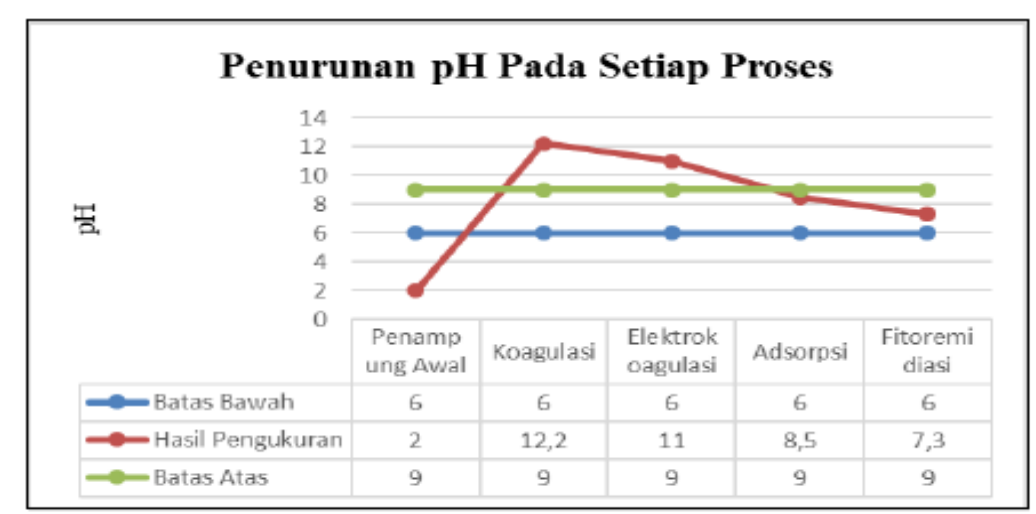

Gambar 2. Grafik Penurunan $\mathrm{pH}$ pada Setiap Proses

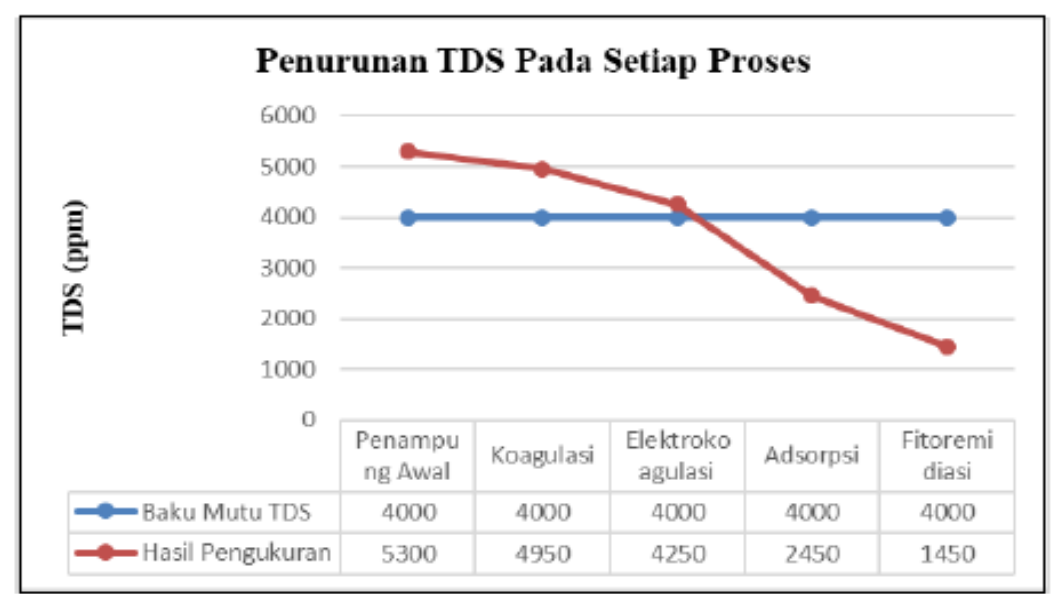

Gambar 3. Grafik Penurunan TDS pada Setiap Proses

Sedangkan data hasil pengujian dilakukan treatment dapat dilihat dalam limbah cair inlet dan outlet setelah Tabel 3.

Tabel 3. Data Inlet dan Outlet Limbah

\begin{tabular}{lcccc}
\hline \multirow{2}{*}{ Parameter } & \multicolumn{2}{c}{ Hasil } & \multicolumn{2}{c}{$\begin{array}{c}\text { Baku Mutu Air } \\
\text { Limbah Permen LH } \\
\text { No.5 Tahun 2014 }\end{array}$} \\
\cline { 2 - 5 } & Menlet & Outlet & Gol. I & Gol. II \\
\hline au & Coklat & Bening & - & - \\
Warna & 5300 & 1450 & 2000 & - \\
TDS (ppm) & 2 & 7,3 & $6,0-9,0$ & $6,0-9,0$ \\
pH & 304 & 92 & - & - \\
Kesadahan Total (ppm) & $<0,251$ & $<0,251$ & 0,1 & 1 \\
Timbal (ppm) & Tidak Menyengat & - & \\
\hline \multicolumn{2}{c}{ Setelah mengetahui seluruh data } & paling besar yaitu sebesar 72,64\%, hasil \\
hasil akhir air treatment dapat dihitung & ini paling besar dibandingan dengan \% \\
efektivitas penurunan parameter dengan & efektivitas Kesadahan total yaitu sebesar \\
hasil perhitungan \% efektivitas TDS & $69,37 \%$. & &
\end{tabular}




\section{PEMBAHASAN}

Prototype alat olah limbah cair laboratorium yang dirancang terdiri dari bak penampung awal, bak koagulasi, bak elektrokoagulasi, bak penampung sementara, pipa adsorpsi dan bak fitoremediasi. Alat ini dirancang secara sederhana dengan kapasitas limbah awal sebanyak 45 Liter. Perlunya mempertimbangkan pemilihan penggunaan metode pengolahan agar dalam kerjanya dapat mereduksi polutan yang terkandung dengan baik sehingga sesuai dengan standar yang telah ditetapkan oleh Kementerian Lingkungan Hidup Nomor 5 Tahun 2004 yakni mengenai baku mutu pada limbah.

Bak Penampung Awal memiliki diameter sebesar $54 \mathrm{~cm}$ x $36.5 \mathrm{~cm}$ x 28.5 $\mathrm{cm}$ dengan kapasitas air limbah 45 liter untuk sekali proses (running). Luas dari bak ini adalah $1.971 \mathrm{~cm}^{2}$. Kapasitas air limbah di dalam bak ini di sesuaikan dengan waktu tinggal yaitu 24 jam. Bak penampung awal ini berfungsi untuk mengatur jumlah debit aliran yang akan masuk ke dalam proses selanjutnya agar dapat selalu berjalan dengan konstan.

Bak Koagulasi memiliki diameter sebesar $(54 \times 36.5 \times 28.5) \mathrm{cm}$. Luas bak ini adalah $1.971 \mathrm{~cm}^{2}$ dengan waktu tinggal di dalamnya yaitu 24 jam, sehingga kapasitas maksimal air sebanyak 35 liter. Air limbah yang berada di bak penampungan awal selanjutnya di alirkan ke bak koagulasi. Didalam bak ini terdapat proses pencampuran dengan kapur tohor yang dilengkapi dengan mixer otomatis agar bubuk kapur dapat tercampur dengan rata hingga homogen.

Bak Elektrokoagulasi, sama halnya dengan bak yang lainnya, bak ini memiliki diameter sebesar $(54 \times 36.5$ x 28.5) $\mathrm{cm}$ dengan luas bak sebesar 1.971 $\mathrm{cm}^{2}$. Alat ini beroperasi selama \pm 4 jam dengan waktu tinggal 24 jam. Kapasitas maksimal di dalam bak ini adalah 30 liter. Elektrokoagulasi dapat diartikan sebagai salah satu teknik untuk menggumpalkan atau mengendapkan pertikel kecil atau partikel halus dengan menggunakan aliran listrik.

Pipa Adsorpsi, pipa adsorpsi ini berbentuk tabung yang dibuat dari paralon ukuran 5 inch dengan tinggi $25 \mathrm{~cm}$. Dalam proses ini tidak memiliki waktu tinggal, sehingga dalam prosesnya terus mengalir secara continue. Didalam tabung adsorpsi ini terdapat absorben yang terdiri dari zeloit dan arang aktif. Kedua adsorben ini berfungsi untuk menjerap zat-zat racun, mengikat bau yang dihasilkan oleh air limbah, dan menjernihkan air limbah tersebut.

Bak Fitoremediasi berbeda dengan bak yang lain, bak fitoremediasi ini memiliki dimensi yang relatif lebih besar jika dibandingkan dengan bak yang lain. Diameter dari bak fitoremediasi ini adalah $=60 \times 41 \times 34 \mathrm{~cm}$. Luas bak ini adalah sebesar $2.460 \mathrm{~cm}^{2}$ dengan waktu tinggal selama 48 jam. Didalam bak ini terdapat filter penyaring air berupa tanah, kerikil, dan pasir, serta tanaman kangkung yang berfungsi meremediasi polutan.

Prototype alat pengolahan limbah yang telah dirancang memiliki kelebihan dan kekurangan. Untuk kelebihannya yaitu seperti membutuhkan ruang yang tidak luas, dapat ditempatkan dimanapun dan mudah dipindahkan karena bentuknya yang portable. Sedangkan kekurangannya yaitu belum bisa mendeteksi volume akhir limbah yang dihasilkan dari proses treatment.

Berdasarkan tabel 1 diketahui bahwa karakteristik awal limbah cair laboratorium yaitu memiliki bau 
menyengat dengan warna kecoklatan, untuk kesdahan total sebesar 304 dan untuk parameter Timbal sudah sesuai dengan baku mutu golongan II yaitu 1 sedangkan hasil pengukuran sebesar $<0,251$. Namun $\mathrm{pH}$ dan TDS belum sesuai dengan baku mutu yang ada yaitu 6,0-9,0 untuk $\mathrm{pH}$ golongan 2, sedangkan hasil pengukuran $\mathrm{pH} 2$ dan baku mutu untuk TDS 4000 sedangkan hasil pengukuran TDS 5300 ppm. Oleh karena itu dilakukan pengolahan agar limbah cair laboratorium berada di bawah baku mutu yang telah ditetapkan sehingga dapat dibuang ke lingkungan secara langsung.

Pada saat dilakukan treatment terjadi penurunan kadar $\mathrm{pH}$ dan kadar TDS pada setiap proses. Dari gambar 2 diketahui penurunan $\mathrm{pH}$ pada setiap proses. $\mathrm{pH}$ awal limbah cair laboratorium yaitu 2, masuk pada proses koagulasi $\mathrm{pH}$ naik menjadi 12 yang berarti lebih dari batas atas $\mathrm{pH}$ dalam baku mutu. $\mathrm{pH}$ saat proses koagulasi naik dikarenakan penambahan koagulan berupa kapur tohor. Kapur tohor sendiri bersifat basa sehingga mempengaruhi $\mathrm{pH}$ limbah cair menjadi bersifat basa. Saat masuk proses elektrokoagulasi $\mathrm{pH}$ mengalami penurunan menjadi 8,5, hasil ini masih melebihi batas atas baku mutu. kemudian masuk proses adsopsi $\mathrm{pH}$ mengalami penurunan lagi menjadi 8,5, hasil ini sudah berada pada range yang aman dalam artian sudah sesuai dengan baku mutu yang ada. Terakhir setelah proses fitoremediasi $\mathrm{pH}$ semakin turun menjadi 7,3, hasil ini masih masuk dalam baku mutu yang ada. Penurunan $\mathrm{pH}$ paling banyak terjadi pada proses adsorpsi.

Sedangkan pada Gambar 3 terlihat penurunan TDS pada setiap proses. Kondisi awal limbah cair yaitu 5300 ppm hasil ini melebihi baku mutu. Setelah masuk koagulasi kadar TDS mengalami penurunan kembali menjadi $4950 \mathrm{ppm}$, hasil ini masih lebihi baku mutu air limbah. Kemudian saat proses elektrokoagulasi kadar TDS turun kembali menjadi $4250 \mathrm{ppm}$, hasil ini hampir mendekati baku mutu yang ada. Pada proses adsoprsi kadar TDS mengalami penurunan yang besar yaitu sampai 2450 ppm, hasil ini sudah dibawah baku mutu yang ada. Terakhir saat masuk fitoremediasi mengalami penurunan sampai 1450 ppm, yang berarti hasil ini sudah dibawah baku mutu yang ada sehingga sudah sesuai dengan baku mutu yang ditetapkan. Dari setiap penurunan TDS dihitung \% efektivitas penurunannya dan didapatkan hasil penurunan TDS paling banyak pada saat proses adsopsi.

Hasil akhir pengukuran parameter secara keseluruhan tercantum pada Tabel 4. Berdasarkan Data pada table ini dapat diketahui bahwa hasil akhir proses treatment memiliki warna bening dan berbau tanah karena setelah melewati proses fitoremediasi. Untuk parameter $\mathrm{pH}$ yaitu bernilai 7,3, TDS sebesar $1450 \mathrm{ppm}$, Kesadahan Total sebesar 92 dan Timbal $<0,251$. Hasil tersebut sudah sesuai dengan baku mutu yang ada. laboratorium ini paling efektif dalam menurunan kadar TDS, karena hasil perhitungan \% efektivitas TDS paling besar yaitu sebesar $72,64 \%$, hasil ini paling besar dibandingan dengan \% efektivitas Kesadahan total yaitu sebesar $69,37 \%$.

\section{KESIMPULAN DAN SARAN}

Berdasarkan hasil perancangan prototype alat olah limbah cair laboratorium dapat disimpulkan bahwa susunan dari prototype alat olah limbah cair laboratorium terdiri dari bak penampungan awal, bak koagulasi, bak 
elektrokoagulasi, bak penampungan sementara, pipa adsorpsi dan bak fitoremediasi.

Efektivitas penurunan TDS paling besar terjadi pada pipa adsorpsi yaitu sebesar $42,35 \%$. Selain itu pada proses ini $\mathrm{pH}$ juga mengalami penurunan paling banyak yaitu dari 11 menjadi 8,5 .

\section{DAFTAR RUJUKAN}

Ananda, E.R., Irawan, D., Wahyuni, S.D., et al. (2017). Pembuatan Alat Pengolah Limbah Cair dengan Metode Elektrokoagulasi untuk Industri Tahu Kota Samarinda, Jurnal Teknologi Terpadu, 6(1), 5459.

Audiana, M., Apriani, I., \& Kadaria, U. (2017). Pengolahan Limbah Cair Laboratorium Teknik Lingkungan Dengan Koagulasi Dan Adsorpsi Untuk Menurunkan COD, Fe, dan $\mathrm{Pb}$. Jurnal Teknologi Lingkungan Lahan Basah, $\quad$ 5(1), 1-10.

Hanum, F., Tambun, R., Ritonga, M.Y., Kasim, W.W. (2015). Aplikasi Elektrokoagulasi Dalam Pengolahan Limbah Cair Pabrik Kelapa Sawit, Jurnal Teknik Kimia USU, 4(4), 1317.

Harjanto, T. R., \& Saipul, B. (2019). Imobilisasi Hasil Samping Pengolahan Limbah Cair Laboratorium Kimia Menjadi Batu Bata Untuk Keamanan Penyimpanan. Jurnal Terpadu Ilmu Kesehatan, 8(2), 141-148.

Indrayani, L., Rahmah, N. (2018). Nilai Parameter Kadar Pencemar Sebagai Penentu Tingkat Efektifitas Tahapan
Pengolahan Limbah Cair Industri Batik, Jurnal Rekayasa Proses, 12(1), 41-50.

Nuraini, E., Fauziah, T., Lestari, F. (2019). Penentuan Nilai BOD dan COD Limbah cair Inlet Laboratorium Pengujian Fisis Politeknik ATK Yogyakarta, Integrated Lab Journal, 7(2), 10-15

Nur, A., Jatnika, A. (2014). Aplikasi Elektrokoagulasi Pasangan Elektroda Aluminium Pada Proses Daur Ulang Grey Water Hotel, Jurnal Teknik Lingkungan, 20 (1), 58-67.

Nurlela, Sari, N.,E.,P., Wardoyo, S., E. (2019). Fitoremediasi Tanah Tercemar Logam Berat Cd Dengan Menggunakan Tanaman Hanjuang (Cordyline Fruticosa), Jurnal Sains Natural Universitas Nusa Bangsa, 9(2), 57-65.

Prabowo, A., Basrori, G.H., Purwanto. (2012). Pengolahan limbah cair yang mengandung minyak dengan proses elektrokoagulasi dengan elektroda besi, Jurnal Teknologi Kimia dan Industri, 1(1), 352-355.

Ratnawati, R., Fatmasari, R.D. (2018). Fitoremediasi tanah tercemar logam timbal (pb) menggunakan tanaman lidah mertua (sansevieria trifasciata) dan jengger ayam (celosia plumosa), Al-Ard: Jurnal Teknik Lingkungan, 3(2), 62-69.

Rosyidah, Dwita. (2014). Pengaruh Tanaman Air Obor (Typha Latifolia) sebagai Fitoremidiasi untuk 
Menurunkan Kadar $\mathrm{Pb}$ Pada Air. Karya Tulis Ilmiah. Poltekkes Kemenkes Yogyakarta.

Siahaan, B.C., Utami, S.,R., Handayanto, E. (2014). Fitoremediasi Tanah Tercemar Merkuri Menggunakan lindernia Crustacea, Digitaria Radicosaa, dan Cyperus Rotundus Serta Pengaruhnya Terhadap Pertumbuhan Dan Produksi Tanaman Jagung, Jurnal Tanah Dan Sumberdaya Lahan, 1(2), 35-51.

Subamia, I.D.P, et al. (2016). Implementasi 3RH (Reduce, Reuse, Recycle, Handle) dalam Manajemen Bahan dan Limbah Laboratorium Kimia Dasar FMIPA Undiksha Sebagai Upaya Efesiensi dan Depolutansi. Prosiding Seminar Nasional FMIPA Undiksha 2016. Cetakan Pertama, Agustus 2016. Universitas Pendidikan Ganesha

Yulianto, A., Hakim, L., Purwaningsih, I., \& Pravitasari, V. A. (2009). Pengolahan Limbah Cair Industri Batik Pada Skala Laboratorium Dengan Menggunakan Metode Elektrokoagulasi. Jurnal Teknologi Lingkungan Universitas Trisakti, 5(1), 6-11. 